\title{
The effect of aminooxy-linkers' structure on the mechanical properties of hyaluronan-oxime hydrogels
}

\author{
Petra Šedová1 ${ }^{* \mathbb{1}}$, Radovan Buffa ${ }^{1}$, Tereza Kočí ${ }^{1}$, Lenka Kovářová ${ }^{1,2}$, Jiři Bednařík ${ }^{1}$, \\ Hana Vágnerová ${ }^{1}$, Vladimir Velebný ${ }^{1}$ \\ ${ }^{1}$ R\&D department, Contipro, Dolní Dobrouč 401, 56102 Dolní Dobrouč, Czech Republic \\ ${ }^{2}$ Brno University of Technology, Faculty of Chemistry, Institute of Physical Chemistry, Purkynova 464/118, 61200 Brno, \\ Czech Republic
}

Received 13 August 2021; accepted in revised form 19 October 2021

\begin{abstract}
The wide range of hydrogel applications is a result of the optimization of gelation. Herein, the various aminooxylinkers were synthesized to study the kinetics of gelation and mechanical properties of hydrogels prepared by crosslinking of aldehyde-modified $\mathrm{N}$-acetylglucosamine (GlcNAc) of hyaluronan ( $\triangle \mathrm{HA}-\mathrm{CHO}$ : 4,5-anhydro-6-(GlcNAc)-oxo hyaluronan or HA-CHO: 6-(GlcNAc)-oxo hyaluronan). Structural characteristics of the linkers (length, number of functional groups and rigidity) and the polymer (effect of the $-\mathrm{C}=\mathrm{C}$ - double bond) were investigated in detail and showed decreasing mechanical stiffness with increasing hydrophobic character of linker and effect of its rigidity/flexibility on imine conversion. Besides known linear bis(aminooxy)alkanes with different lengths of the chain, new multifunctional aminooxy-linkers: 1,3,5tris(aminooxymethyl)benzene and multikis(6-aminooxy-6-deoxy)- $\beta$-cyclodextrin were prepared and shortened the gelation time. The MTT (3-(4,5-dimethylthiazol-2-yl)-2,5-diphenyltetrazolium bromide) analysis showed that despite the aminooxylinkers' cytotoxicity at higher concentrations, the final oxime hydrogels are non-cytotoxic and therefore are suitable for medicinal applications.
\end{abstract}

Keywords: polymer gels, hyaluronan, rheology, oxyamine

\section{Introduction}

In the last decades, modern medicine has applied new substitutes, often in hydrogel form prepared in situ, for the replacement of damaged tissues. Therefore, knowledge of reaction kinetics and stability of the crosslinking is useful. The methods of hydrogel preparation were usually based on a mixing of two liquid components, and gelation resulted from their efficient crosslinking reactions in a hydrophilic medium. Moreover, hydrogels are utilized in drug delivery, wound healing, tissue regeneration, and as tissue adhesives [1]. Suitable mechanical properties, appropriate biocompatibility and the ability to support cell growth and proliferation are essential parameters required for these healing materials. Therefore, hyaluronic acid (HA), a linear polysaccharide naturally occurring in the human body, is favoured to design scaffolds [2]. HA is present through all steps of the wound healing process as a component of the wound environment but also as a factor that actively modulates tissue regeneration [3]. HA application in tissue engineering suffers from a lack of mechanical stiffness and hydrolytic stability that could be improved by its modification, e.g. crosslinking [4]. Each crosslinking method is associated with advantages and disadvantages, e.g., kinetics, cytotoxicity, temperature $/ \mathrm{pH} /$ reactive oxygen species responsivity and water resistance, which affected the choice of linkers. Novel hydrogels were simply crosslinked via reversible interactions, for example, hydrolytically 
cleavable imine. Apart from the common hydrazoneHA-hydrogels [5] the oxime-HA-hydrogels have also been prepared either from HA-dialdehyde synthesized using sodium periodate [6], or by application of HA-monoaldehyde prepared by deprotection of dimethoxy acetal-substituted HA [7], or using the reducing end of HA [8], or by crosslinking of HAketone [9] with aminooxy-poly(ethylene glycol) (aminoxy-PEG) [6] or with hyperbranched aminooxypolyglycerol [10]. These oxime hydrogels have recently been proposed for personalized medical devices in the human nervous system [6], or for preparation of HA-liposomes as targeting particulate carriers applied in drug or vaccine delivery [8], for prevention of postoperative adhesion of tissues [11], or a vitreous substitute for the treatment of retinal detachment [12] and for using as a model patient-derived cells and cell lines for in vitro breast cancer culture [9].

It is well known that crosslinking density and the way of the conjugation influence many characteristics of hydrogels such as self-arrangement, biodegradability, swelling degree, mechanical degradability and hydrolytic stability. However, the influence of the structure of aminooxy-linkers on oximeHA hydrogels has not been investigated in detail yet. This study follows our last investigation about hydrogels prepared by hydrazide crosslinking [13] of non-cytotoxic aldehyde-modified hyaluronan (saturated polyaldehyde hyaluronan $\mathrm{HA}-\mathrm{CHO}[14]$ and unsaturated polyaldehyde hyaluronan $\triangle \mathrm{HA}-\mathrm{CHO}$ [15]). Due to the lower stability of imine bonds of hydrazone, we prepared stiffer HA hydrogels crosslinked with a broad range of aminooxy-linkers. It is generally known that using aminooxy-linkers instead of amino or hydrazido analogues enhances the stability of hydrogels [16]. Stability of oxime in different $\mathrm{pH}$ is important in the healing of wounds, as $\mathrm{pH}$ value can be changed rapidly with therapeutic interventions [17]. Although it is known that gelation rate is dependent mainly on polymer concentration, the reactivity of carbonyl functional group (HA-aldehyde/ketone) was compared for modulation of gelation rate recently [9].

In this research, there was investigated the impact of aminooxy-linker parameters, namely number of aminooxy groups, length and chain mobility, on conjugation with hyaluronan, gelation time and mechanical properties of hydrogels formed by crosslinked hyaluronan. The effect of imine (Schiff base) stabilization by an adjacent double bond in unsaturated polyaldehyde hyaluronan ( $\triangle \mathrm{HA}-\mathrm{CHO}$ : 4,5-anhydro6-(GlcNAc)-oxo hyaluronan) in comparison with the HA-CHO was observed for imine [15] and hydrazone hydrogels [13] and had potentials to increase the conversion to oxime and the stiffness of hydrogels as well. We supposed that more rigid aminooxylinkers, namely benzene-oxyamines and multikis(6oxyamine-6-deoxy)- $\beta$-cyclodextrin (4), that could increase the mechanical stiffness of the hydrogel and decelerate their reaction rate with $\mathrm{HA}-\mathrm{CHO} / \Delta \mathrm{HA}$ CHO. 4 was designed as a crosslinker because of its high number of aminooxy groups and its ability to entrap variety of guest molecules in the cavity of the cyclic chain. Therefore we compared rigid 1,4bis(aminooxymethyl)benzene (2) with more flexible $N, N^{\prime}$-bis(aminooxy)alkanes (1a-1e) (Figure 1).

\section{Experimental}

\subsection{Material}

The sodium salt of hyaluronic acid and HA-CHO, commercially available as sodium formyl hyaluronate $\left(M_{\mathrm{w}}=342 \mathrm{~kg} / \mathrm{mol}\right.$, DS $9 \%$, DC 5\%) were provided by Contipro, Czech Republic. Adipic dihydrazide $(\mathrm{ADH}), \alpha, \alpha^{\prime}$-dibromo- $p$-xylene and hydrazine hydrate were purchased from TCI Europe. 1,2-dibromoethane

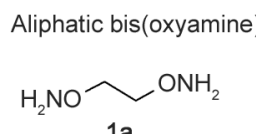

$1 \mathrm{a}$

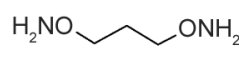

$1 \mathrm{~b}$

Aromatic bis(oxyamine)/tris(oxyamine)
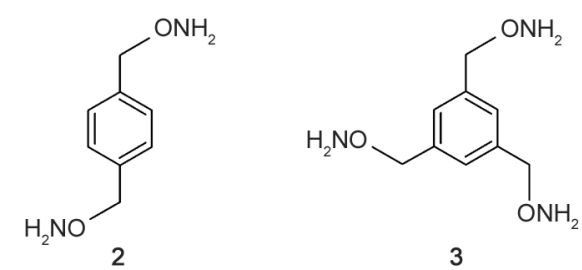
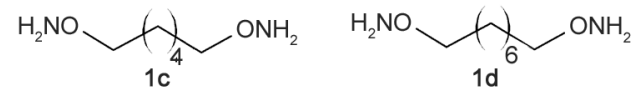

$\mathrm{H}_{2} \mathrm{NO}{ }_{1 e^{8}} \mathrm{ONH}_{2}$

Multikis(oxyamine)- $\beta$-cyclodextrin

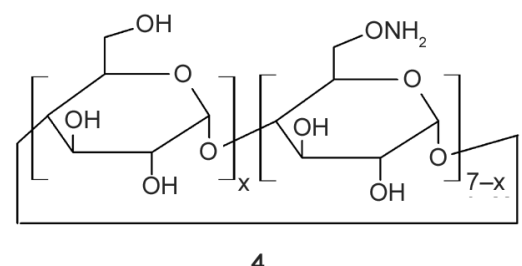

Figure 1. Chemical structure of aminooxy-linker used for crosslinking of $\mathrm{HA}-\mathrm{CHO} / \triangle \mathrm{HA}-\mathrm{CHO}$. 
and 1,6-dibromohexane, 1,8-dibromooctane, 1,6-diaminohexane, $\mathrm{O}, \mathrm{O}^{\prime}-1,3$-propanediylbishydroxylamine dihydrochloride (1b), $N$-hydroxyphthalimide (NHPI), 1,10-dibromodecane, 1,3,5-tris(bromomethyl)benzene were purchased from Sigma-Aldrich, Czech Republic. Diisopropylethylamine (DIPEA) was purchased from Iris Biotech, Germany. Hydrochloric acid, tetrahydrofuran (THF), sodium chloride, sodium bicarbonate, sodium acetate and disodium hydrogen phosphate dodecahydrate were purchased from Lach-Ner, Czech Republic. $\mathrm{D}_{2} \mathrm{O}$ (99.8\%), Dimethyl sulfoxide- $d_{6}$ (DMSO- $d_{6}, 99.9 \%$ ) were used as obtained from CortecNet, France. Absolute ethanol and triethylamine (TEA) were purchased from Ing. Petr Švec-PENTA, Czech Republic. Acetonitrile, methanol HPLC grade, dimethylsulfoxide was purchased from VWR International, France. Heptakis(6bromo-6-deoxy)- $\beta$-cyclodextrin (CD-Br) was purchased from AraChem, Netherlands. 3-(4, 5-dimethylthiazol-2-yl)-2,5-diphenyltetrazolium bromide (MTT) was purchased from Life Technologies. Deionized water was used for all experiments.

\subsection{Synthesis of $N, N^{\prime}$-bisaminooxyalkanes}

The synthesis includes two steps (Figure 2): nucleophilic substitution of dibromoalkane by $N$-hydroxyphthalimide, known as Gabriel synthesis of phthalimide, followed by deprotection with hydrazine.

\subsubsection{Synthesis of phthalimides}

Dibromoalkane (0.02 mol: 1,2-dibromoethane, 1,6dibromohexane, 1,8-dibromooctane, 1,10-dibromodecane and 1,4-bis(bromomethyl)benzene) and $N$-hydroxyphthalimide $(0.042 \mathrm{~mol})$ were suspended in anhydrous THF $(20 \mathrm{ml})$ at room temperature for two hours. Diisopropylethylamine $(0.05 \mathrm{~mol})$ and dimethyl sulfoxide $(20 \mathrm{ml})$ were subsequently added. The red reaction solution was stirred at $75^{\circ} \mathrm{C}$ for $6-$ 24 hours under a nitrogen atmosphere to form an orange suspension. The $N, N^{\prime}$-alkylbis(oxyphthalimide) was precipitated, and the crude product was washed with cold water and finally with ethyl acetate. The

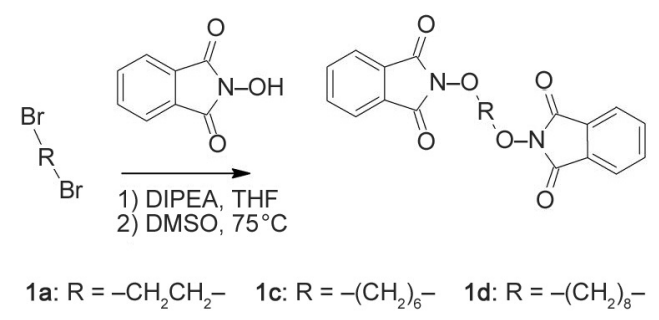

Figure 2. Synthesis of bis(oxyamine). final $N, N^{\prime}$-alkylbis(oxyphthalimide) was dried under reduced pressure.

${ }^{1} \mathrm{H}$ NMR (500 MHz, DMSO- $\left.d_{6}\right): \delta 7.85$ (s, 8H, phthalimide), $\delta 4.13$ (t, 4H, O-CH $\mathrm{CH}_{2-}^{-}$), $\delta$ 1.8-1.2 (alkyl backbone).

\subsubsection{Deprotection of phthalimides with hydrazine}

The $N, N^{\prime}$-alkylbis(oxyphthalimide) $(0.02 \mathrm{~mol})$ was suspended in ethanol with hydrazine hydrate $(0.1-$ $0.2 \mathrm{~mol}$ ) and mixed at room temperature for several hours and then heated at $60^{\circ} \mathrm{C}$ for 24 hours. Product was filtered, the solid part (mainly phthalhydrazide) was washed with 2-propanol $(3 \times 50 \mathrm{ml})$, and combined liquid fractions were evaporated under reduced pressure. The hydrazine excess, analyzed after modification with benzaldehyde at $310 \mathrm{~nm}$ after Reversed Phase - High Performance Liquid Chromatography (RP-HPLC) separation, was removed by repeated co-distillation with water. The crude product was dissolved in demineralized water at a concentration of $10 \%(\mathrm{w} / \mathrm{v})$, and the $\mathrm{pH}$ of the solution was adjusted by $1 \mathrm{M} \mathrm{HCl}$ to $2-3$. The final $N, N^{\prime}$-bisaminooxyalkane hydrochloride was separated by solvent evaporation at low pressure and then purified by washing with an excess of 2-propanol.

\subsection{Synthesis of}

\section{1,3,5-tris(aminooxymethyl)-benzene (3)}

The synthesis of the trifunctional linker was analogous to the synthesis of a bifunctional linker, only the amount of reagents for phthalimidation was higher $(0.066 \mathrm{~mol}$ NHPI and $0.072 \mathrm{~mol}$ DIPEA to $0.02 \mathrm{~mol}$ 1,3,5-tris(bromomethyl)benzene).

\subsection{Synthesis of multikis(6-}

aminooxy-6-deoxy)- $\beta$-cyclodextrin (4)

$\mathrm{CD}-\mathrm{Br}(1.90 \mathrm{mmol})$ was dissolved in $30 \mathrm{ml}$ dimethyl sulfoxide (DMSO: dried on molecular sieve $4 \AA$ ). NHPI (17.1 mmol) and sodium bicarbonate (20.9 mmol) as a base were added. The dark red reaction mixture was stirred at $60^{\circ} \mathrm{C}$ for $72-96$ hours

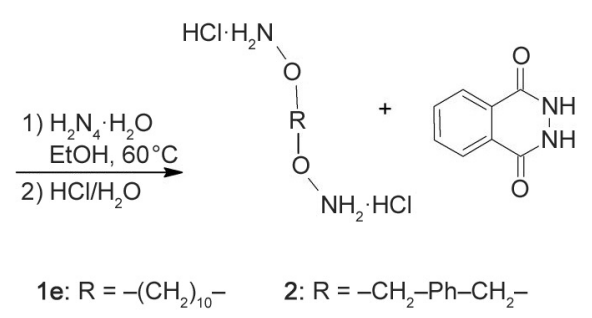


to form $N$-oxyphthalimide of cyclodextrin. Hydrazine hydrate $(38 \mathrm{mmol})$ was used in hydrazinolysis at $60^{\circ} \mathrm{C}$ for 24 hours. The cyclodextrin derivative was isolated by precipitation using 2-propanol. The crude product was dissolved in demineralized water at a concentration $10 \%(\mathrm{w} / \mathrm{v})$, and the $\mathrm{pH}$ of the solution was adjusted by $1 \mathrm{M} \mathrm{HCl}$ to $\mathrm{pH} 2-3$. Solid-phase, formed by phthalhydrazide, was removed by filtration, and a mixture of products was obtained from the liquid phase, which was dried by evaporation. The mixture of oxyaminated cyclodextrins was separated into cyclodextrin derivatives with a different number of aminooxy groups by two-step ion-exchange chromatography.

\subsection{Separation of oxyaminated cyclodextrins}

Separations were conducted on Äkta pure system (GE Healthcare Bio-Sciences, USA) with UV detector, and chromatograms were recorded at $210 \mathrm{~nm}$. In the first step, sample (up to $200 \mathrm{mg}$ of crude reaction product) was dissolved in deionized water and loaded on anion exchange sorbent Q Ceramic HyperD $\mathrm{F}, 50 \mu \mathrm{m}$ (Pall Corporation, USA) in a glass column $(15 \times 200 \mathrm{~mm}$ with the approx. bed size $110 \mathrm{~mm})$. The mobile phase consisted of A water and B $250 \mathrm{mM}$ $\mathrm{NaCl}$. Gradient elution was used under the following conditions: 0-22 $\min 4 \%$ B isocratically, 22-27 min linear increase from $4 \%$ to $100 \% \mathrm{~B}, 27-57 \mathrm{~min}$ $100 \% \mathrm{~B}$ isocratically. The flow rate was $5 \mathrm{ml} / \mathrm{min}$. A fraction containing oxyaminated cyclodextrins was collected in $0-10 \mathrm{~min}$.

This fraction was further separated in a second step. The sample was diluted in $10 \mathrm{mM} \mathrm{NaCl}$ with $\mathrm{pH}$ adjusted to 2 with $\mathrm{HCl}$ and then loaded on cation exchange resin Macro-Prep High S Media, $50 \mu \mathrm{m}$ (BioRad, USA $)$ in a glass column $(15 \times 200 \mathrm{~mm}$ with the approx. bed size $110 \mathrm{~mm}$ ). The mobile phase consisted of $\mathrm{A} 10 \mathrm{mM} \mathrm{NaCl}$, pH 2 and B $10 \mathrm{mM} \mathrm{Na}_{2} \mathrm{HPO}_{4}$, $\mathrm{pH}$ 7. Gradient elution was used under the following conditions: $0-12 \mathrm{~min} 0 \% \mathrm{~B}$ isocratically, $12-27 \mathrm{~min}$ linear increase from 0 to $67 \% \mathrm{~B}, 27-67$ min linear increase from 67 to $73 \% \mathrm{~B}, 67-82$ min linear increase from 73 to $100 \% \mathrm{~B}, 82-122 \mathrm{~min} 100 \% \mathrm{~B}$ isocratically. The flow rate was $5 \mathrm{ml} / \mathrm{min}$. Fractions of individual cyclodextrins were collected as separated peaks, followed by desalting using solid-phase extraction (SPE) on columns Supelclean ENVI-Carb. Columns Supelclean ENVI-Carb, $2 \mathrm{~g}$ (Sigma-Aldrich, Czech Republic) were conditioned with $18 \mathrm{ml}$ of acetonitrile, $18 \mathrm{ml}$ of $50 \%$ acetonitrile and $18 \mathrm{ml}$ of water. Then the sample was loaded, and the column was washed with $20 \mathrm{ml}$ of water. The sample was eluted with $20 \mathrm{ml}$ of $25 \%$ acetonitrile and $20 \mathrm{ml}$ of $50 \%$ acetonitrile. Samples were dried under vacuum, redissolved in water and freeze-dried. Mass spectra were used for the analysis of products purified by chromatography. Peak areas of ions with $\mathrm{m} / \mathrm{z}$ corresponding to $[\mathrm{M}+\mathrm{H}]^{+}$of cyclodextrins with a different number of aminooxy groups were obtained from the MS chromatograms. The percentual composition of the fraction was then estimated as the peak area of individual cyclodextrin divided by the sum of areas of all cyclodextrin peaks.

\subsection{Synthesis of HA-CHO/AHA-CHO}

HA-CHO $\left(M_{\mathrm{w}}=47 \mathrm{~kg} / \mathrm{mol}\right.$, DS $40 \%$, DC $\left.10 \%\right)$ was prepared using Dess-Martin periodinane, and 4,5-anhydro-6(GlcNAc)-oxo hyaluronan $\left(M_{\mathrm{w}}=10 \mathrm{~kg} / \mathrm{mol}\right.$, DS $30 \%$, DS* $10 \%$ ) was prepared by the $\beta$-elimination of HA-CHO according to Šedová et al. [13].

\subsection{Nuclear magnetic resonance (NMR) analysis}

The NMR analyses were performed on Bruker Avance Neo $700 \mathrm{MHz}$ equipped with BBI plus probe. The ${ }^{1} \mathrm{H}$ chemical shifts were expressed in ppm $(\delta)$ referenced to 3-trimethylsilylpropanoic acid sodium salt (TSPA) used as an internal standard. All samples $(10 \mathrm{mg})$ were dissolved in $\mathrm{D}_{2} \mathrm{O}(0.8 \mathrm{ml})$ and transferred into $5 \mathrm{~mm}$ NMR quartz tubes.

The structure of phthalimide derivatives (in DMSO$d_{6}$ ) and aminooxy-linkers (in $\mathrm{D}_{2} \mathrm{O}$ ) were confirmed by NMR.

Substitution degree of HA-CHO (DS) was determined using the signal of the hydrated aldehydic group $\left(\mathrm{C}_{6} \mathbf{H}-(\mathrm{OH})_{2}-\mathrm{GlcNAc}\right)$ at chemical shift $5.23 \mathrm{ppm}$, of $\triangle \mathrm{HA}-\mathrm{CHO}\left(\mathrm{DS}^{*}\right)$ using the signal of $\mathrm{C}_{6} \mathrm{CHO}-\mathrm{GlcNAc}$ at $9.24 \mathrm{ppm}$ and carboxylation degree (DC) was reported elsewhere [13].

The contents of imino conjugates of HA-CHO or $\triangle \mathrm{HA}-\mathrm{CHO}$ were determined by ${ }^{1} \mathrm{H}$ NMR spectroscopy. The samples were dissolved in $\mathrm{D}_{2} \mathrm{O}$ or deuterated buffer $(10 \mathrm{mg} / 0.8 \mathrm{ml})$. The degree of conversion of aldehyde to imine/oxime (DI) was defined as the molar ratio (integral) of imino proton $-\mathrm{CH}=\mathrm{NH}-$ in the sum of areas between 7.50-7.70 and 6.75$6.90 \mathrm{ppm}$ ( $\mathrm{Z}$ and $\mathrm{E}$ isomers) related to the initial amount of all aldehydes (HA-CHO and $\triangle \mathrm{HA}-\mathrm{CHO}$ ). 


\subsection{Molecular weight $\left(M_{\mathrm{w}}\right)$ of derivatives [kg/mol]}

Molecular weights both of aldehyde-modified hyaluronan (HA-CHO and $\triangle \mathrm{HA}-\mathrm{CHO}$ ) were determined using Size-Exclusion Chromatography coupled to Multi-Angle Light Scattering as previously described by Šedová et al. [13].

\subsection{ESI-MS analysis}

The mass spectrometry (MS) analyses of oxyaminated cyclodextrins were performed on Waters 2545 binary gradient module connected to mass spectrometer Waters SQ Detector 2 (Waters, USA) equipped with an electrospray ionization source operating in positive mode. Cyclodextrins were detected with following instrumental parameters: capillary source voltage $3.5 \mathrm{kV}$, cone voltage $70 \mathrm{~V}$, desolvation temperature $450^{\circ} \mathrm{C}$, desolvation gas (nitrogen) flow $5002 / \mathrm{h}$. Mass spectra were recorded in the range 50 $2000 \mathrm{~m} / \mathrm{z}$ and processed with MassLynx software (Waters, USA).

Samples were dissolved in water $(1 \mathrm{mg} / \mathrm{ml}) .20 \mu 1$ of the solution were injected on column Jupiter $4 \mu \mathrm{m}$ Proteo $90 \AA$, 250×4.6 mm (Phenomenex, Germany). The mobile phase consisted of A $0.1 \%$ formic acid in water and $\mathrm{B}$ methanol. Following gradient was used: $0-10$ min linear increase from 10 to $90 \% \mathrm{~B}$, 10-11 min linear increase from 90 to $100 \%, 11-$ $12 \mathrm{~min} 100 \%$ B isocratically, $12-14$ min linear decrease from 100 to $10 \% \mathrm{~B}$ and $14-21 \mathrm{~min} 10 \% \mathrm{~B}$ isocratically. The flow rate was $1 \mathrm{ml} / \mathrm{min}$.

\subsection{Cell viability assay}

Cell viability was determined using the methodology reported in the literature [13]. The material was considered non-cytotoxic if the viability was higher than $80 \%$ of control.

\subsection{Preparation of hydrogels}

The HA-CHO or $\triangle \mathrm{HA}-\mathrm{CHO}$ was dissolved overnight in $0.9 \% \mathrm{NaCl}$ (or $0.01 \mathrm{M}$ acetate buffer) with $\mathrm{pH}$ value of 6 . An adequate amount of linker was dissolved in the same solvent. The $\mathrm{pH}$ of the aminooxylinker solution was adjusted by $10 \mathrm{mM} \mathrm{NaOH}$ to the $\mathrm{pH}$ of 6 following by its addition and stirring with the solution of HA derivatives. The ratio of aldehydic to aminooxy or amine groups was $1: 1$. The solutions were injected into Teflon moulds and kept at room temperature for 24 hours in order to form hydrogels. Swelling and mechanical properties (Young's modulus) of hydrogel with similar mass were measured under standard laboratory conditions (temperature, pressure, humidity).

\subsection{Viscoelastic and mechanical hydrogel characterization}

\subsubsection{Determination of gelation time $\left(T_{\mathrm{g}}\right)$}

The gelation was measured on Kinexus (MALVERN) using a parallel plate $(40 \mathrm{~mm})$ geometry and $400 \mu \mathrm{m}$ gap. $525 \mu 1$ of the solution was added to the plate, and pre-shear $2000 \mathrm{~s}^{-1}$ for $1 \mathrm{~s}$ was used to homogenize the solutions. An oscillation time sweep at a frequency of $1 \mathrm{~Hz}$ and displacement $0.001 \mathrm{rad}$ was performed at $37^{\circ} \mathrm{C}(n=5)$ [18]. The gelation time was determined as the cross over point of the storage modulus $\left(G^{\prime}\right)$ and the loss modulus $\left(G^{\prime \prime}\right)$.

\subsubsection{Measurement hydrogel viscoelastic characterization}

The rheological properties of the hydrogels were measured on Kinexus (MALVERN) using a crosshatched surface geometry to avoid slippage of the hydrogel. A strain sweep test with a frequency of $1 \mathrm{~Hz}$, and a displacement range of 0.001 to $2 \mathrm{rad}$ was performed $(n=5)$. Elastic modulus was determined at the displacement of $0.1 \mathrm{rad}$. Hydrogels were prepared in Teflon moulds with similar mass $(1700 \pm 300 \mathrm{mg})$.

\subsubsection{Determination of mechanical properties of hydrogels}

The mechanical properties of the hydrogels were measured in compression mode using a Single Column Materials Testing System (Instron 3342). The testing speed was set to $2 \mathrm{~mm} / \mathrm{min}$. The capacity of the Instron 3342 device was $500 \mathrm{~N}$, and the capacity of the compression plate was $100 \mathrm{~N}$. Young's modulus $(E)$ was measured minimally in five independent repetitions, values were averaged, and the standard deviations of the mean $(S D)$ were calculated. Hydrogels were prepared in Teflon moulds with similar mass $(400 \pm 100 \mathrm{mg})$.

\subsubsection{Determination of swelling degree $S W$ [\%]} $400 \pm 100 \mu \mathrm{l}$ hydrogels were weighed immediately after preparation $\left(m_{1}\right)$. After 24 hours, the prepared hydrogels were placed in $5 \mathrm{ml}$ of phosphate-buffered saline (PBS, 0.1 M, pH 7.4 or pH 6.0) at room temperature and weighed $\left(m_{2}\right)$ after 1,4 , and 7 days. According to Equation (1), the swelling degree was calculated with at least five replicates for each sample. 
$S W=\frac{m_{2}}{m_{1}} \cdot 100 \%$

\section{Results and discussion}

\subsection{Synthesis of $\mathrm{N}$-aminooxylinkers}

This study aimed to compare the structural factor of aminooxy-linkers and evaluate the effect of the different number of aminooxy groups, the chain's length and flexibility, on their hydrogel properties and the gelation time. Due to the limited availability of different structural aminooxy-linkers, we synthesized most of the aminooxy-linkers used in this study.

$N, N^{\prime}$-bis(aminooxy)alkanes were usually prepared by Gabriel synthesis, where the synthesis of phthalimides was performed in problematic dimethylformamide $[19,20]$. Therefore, DMSO was used to avoid possible problems with by-products and their toxicity. The change of solvent led to a similar yield of $O, O^{\prime}-1,2$-Ethanediyl-bishydroxylamin dihydrochloride (1a): $25 \%$, in comparison with the synthesis in dimethylformamide (yield $20 \%$ over two steps: Yi et al. [21]). The yield of bis(oxyamine) over two steps (preparation of phthalimides and subsequently oxyamines) were: $O, O^{\prime}-1,6$-Hexanediyl-bishydroxylamin dihydrochloride (1c): 40\%, $O, O^{\prime}-1,8$-Octanediyl-bishydroxylamin dihydrochloride (1d): $75 \%, O, O^{\prime}-1,10$-Decanediyl-bishydroxylamin dihydrochloride (1e): $45 \%$. Results, unfortunately, proved that base (triethylamine) with higher toxicity according to $\mathrm{LD}_{50}$ Oral-Rat led to higher yields than the less toxic DIPEA or non-toxic inorganic base (sodium bicarbonate) (e.g. yields of $N, N^{\prime}$-hexylbis(oxyphthalimide) with base TEA, DIPEA, $\mathrm{Na}_{2} \mathrm{CO}_{3}: 90,80$, $50 \%$ ). It was found that a higher concentration of
DMSO in the solvent mixture led to a higher phthalimide formation. The deprotection of the phthalimide group was achieved by hydrazinolysis in a heterogeneous phase [22] and confirmed by ${ }^{1} \mathrm{H},{ }^{13} \mathrm{C}$, HSQC NMR spectroscopy as the disappearance of aromatic protons ( $\delta 7.86 / 124$ and $135 \mathrm{ppm})$ and protons at $-\mathrm{CH}_{2}$-oxyphthalimide ( $\left.\delta 4.15 / 77 \mathrm{ppm}\right)$. The structure of the intermediate and bis(aminooxy)linkers (Table 1) was confirmed by NMR spectroscopy. The chemical shifts slightly decreased by protonation if the $\mathrm{pH}$ value of the solution was changed by adding hydrochloric acid when free amines were turned into the hydrochloride salt.

Multifunctional linkers: 3 (1,3,5-tris(aminooxymethyl) benzene) and 4 (multikis(6-aminooxy)- $\beta$-cyclodextrin) were also prepared from bromoderivative by phthalimide hydrazinolysis with a higher amount of hydrazine hydrate (10-50 eq per molecule). The 1,3,5-phthalimide benzene was found hardly soluble in DMSO, and therefore NMR intermediate analysis in solution was impossible. The yield of 1,3,5-tris (aminooxymethyl)benzene hydrochloride was $45 \%$ yield over two steps. The structure of $\mathbf{3}$ was confirmed by ESI-MS analysis and NMR spectroscopy.

At the first step of $\mathbf{4}$ preparation, different bases (11 eq DIPEA or $\mathrm{NaHCO}_{3}$ ) were used to influence the conversion. The use of DIPEA instead of $\mathrm{NaHCO}_{3}$ surprisingly resulted in a lower conversion of $\mathrm{CD}-\mathrm{Br}$ during multikis(6-oxyphthalimide)- $\beta$-cyclodextrin synthesis. Probably steric hindrance led to a lower reaction rate in comparison with bis(oxyphthalimide)alkanes. For quantitative conversion, the reaction time has been significantly longer $\left(3-4\right.$ days $\left./ 60^{\circ} \mathrm{C}\right)$. The hydrazinolysis of a cyclodextrin phthalimide led to a multifunctional aminooxy-linker with a different

Table 1. The results of ${ }^{1} \mathrm{H},{ }^{13} \mathrm{C}$ NMR $\left(500 \mathrm{MHz}, \mathrm{D}_{2} \mathrm{O}\right)$ analysis of aminooxy-linkers. $\log P$ was calculated by ACD/Chemsketch 12.01 .

\begin{tabular}{|c|c|c|c|c|c|c|c|c|c|c|c|c|}
\hline \multirow{2}{*}{ No. $\mathrm{CH}_{2}$} & \multicolumn{2}{|c|}{$1 \mathrm{a}$} & \multicolumn{2}{|c|}{$1 \mathrm{c}$} & \multicolumn{2}{|c|}{ 1d } & \multicolumn{2}{|c|}{$1 \mathrm{e}$} & \multicolumn{2}{|c|}{2} & \multicolumn{2}{|c|}{3} \\
\hline & ${ }^{1} \mathrm{H}: \delta$ & ${ }^{13} \mathrm{C}: \delta$ & ${ }^{1} \mathrm{H}: \delta$ & ${ }^{13} \mathrm{C}$ & ${ }^{1} \mathbf{H}: \delta$ & ${ }^{13} \mathrm{C}$ & ${ }^{1} \mathrm{H}: \delta$ & ${ }^{13} \mathrm{C}$ & ${ }^{1} \mathrm{H}: \delta$ & ${ }^{13} \mathrm{C}$ & ${ }^{1} \mathbf{H}: \delta$ & ${ }^{13} \mathrm{C}$ \\
\hline 1 & 4.37 & 72.3 & 4.06 & 76.1 & 4.03 & 75.9 & 4.00 & 75.7 & 5.13 & 76.5 & 5.19 & 76.6 \\
\hline 2 & & & 1.68 & 28.1 & 1.66 & 26.8 & 1.66 & 26.9 & & & & \\
\hline 3 & & & 1.41 & 25.5 & 1.37 & 24.6 & 1.36 & 24.8 & & & & \\
\hline 4 & & & & & 1.33 & 28.6 & 1.29 & 28.6 & & & & \\
\hline 5 & & & & & & & 1.29 & 28.6 & & & & \\
\hline $\mathrm{Ar}$ & & & & & & & & & 7.57 & 129.9 & 7.67 & 131.1 \\
\hline$[\mathrm{M}+\mathrm{H}]^{+}$ & & & 149.28 & & & & & & & & 214.16 & \\
\hline $\log P$ & \multicolumn{2}{|c|}{$-0.37 \pm 0.51$} & \multicolumn{2}{|c|}{$0.91 \pm 0.48$} & \multicolumn{2}{|c|}{$1.98 \pm 0.48$} & \multicolumn{2}{|c|}{$3.04 \pm 0.48$} & \multicolumn{2}{|c|}{$0.88 \pm 0.51$} & \multicolumn{2}{|c|}{$0.21 \pm 0.54$} \\
\hline
\end{tabular}

$\mathrm{H}_{2} \mathrm{NO}_{1}>^{2}>4>->_{4}>-1>\mathrm{ONH}_{2}$ 


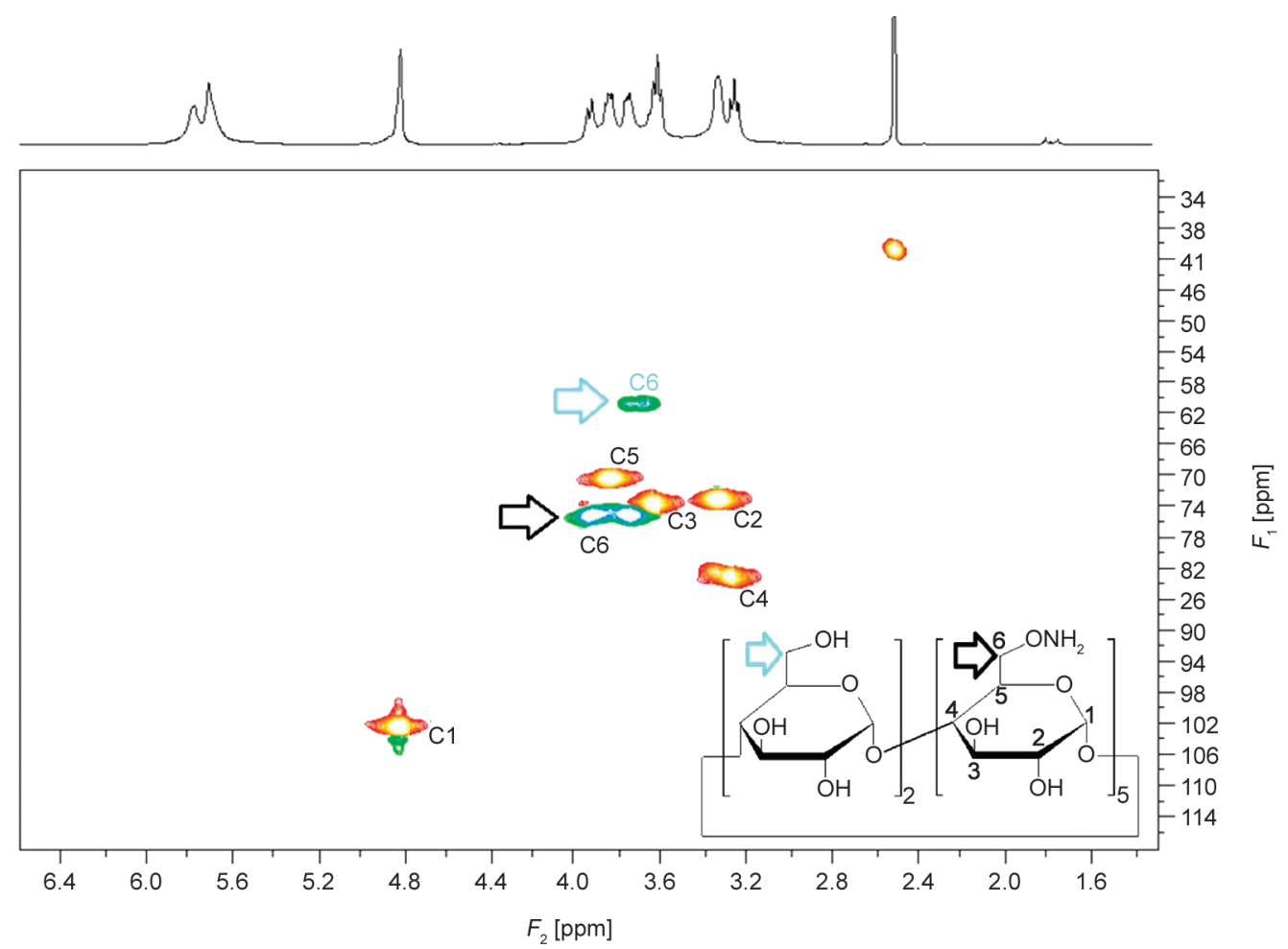

Figure 3. HSQC NMR (DMSO- $\left.d_{6}\right)$ spectrum of the fraction of 4 after chromatographic separation.

number of aminooxy groups, randomly distributed among pyranose cycles. Therefore the crude product was chromatographically separated to $\mathbf{4}$ with a welldefined substitution of the primary hydroxyl groups. The HSQC was used for the analysis of 4 (the chemical shifts were assigned in Figure 3). The splitting of peak $\mathrm{C} 6$ into two signals in both functional groups: $-\mathrm{CH}_{2}-\mathrm{OH}$ and $-\mathrm{CH}_{2}-\mathrm{ONH}_{2}$ is caused by the presence of neighbouring chiral carbons $\mathrm{C} 5$. In the case of $-\mathrm{CH}_{2} \mathrm{OH}$, the signals of diastereotopic hydrogens are much closer because of less fixed rotation of the bond between carbons $\mathrm{C} 5$ and $\mathrm{C} 6$ in comparison to the bulkier (more fixed) $-\mathrm{CH}_{2} \mathrm{ONH}_{2}$ group.

\subsection{The chromatography of cyclodextrin derivatives}

The crude reaction mixture of cyclodextrin derivatives was firstly separated from phthalderivatives (phthalhydrazide, phthalanhydride, phthalamic acid derivate) by anion exchange chromatography (Figure 4). The mixture of cyclodextrin derivatives, collected in the first fraction $(0-10 \mathrm{~min})$ with a different number of aminooxy groups instead of the primary hydroxyl group, was subsequently separated by cation exchange chromatography. The sample was acidified before the separation to retain the derivatives during the separation. The cyclodextrins were then eluted by increasing the $\mathrm{pH}$ of the mobile phase

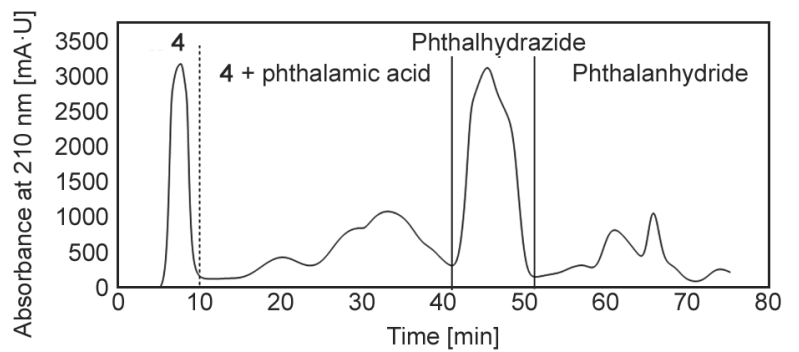

Figure 4. UV chromatogram of the crude product after derivatization of cyclodextrins (200 $\mathrm{mg}$ of the sample) on anion exchange column under following gradient conditions: A - water, $\mathrm{B}-250 \mathrm{mM} \mathrm{NaCl}$; 0-27 $\min 4 \% \mathrm{~B}$ isocratically, 27-44 min linear increase from $4 \%$.

rather than by increasing salt concentration. The collected fractions were analyzed by LC-MS (Table 2). Although the cyclodextrins were not fully separated, collected fractions usually contained only 1 or 2 major derivatives.

\subsection{The cytotoxicity assay}

The cytotoxicity of linkers was examined by MTT assay to evaluate the potential application of oxime hydrogels in the biomedical field. It was shown that the viability of 3T3 mouse fibroblast cells after treatment with 1c, 1e, 2, 3, was not significantly changed in lower concentration $(10-100 \mu \mathrm{g} / \mathrm{ml})$ commonly used for hydrogel formation in the whole monitored 
Table 2. The composition of cyclodextrins derivatives identified by MS spectroscopy.

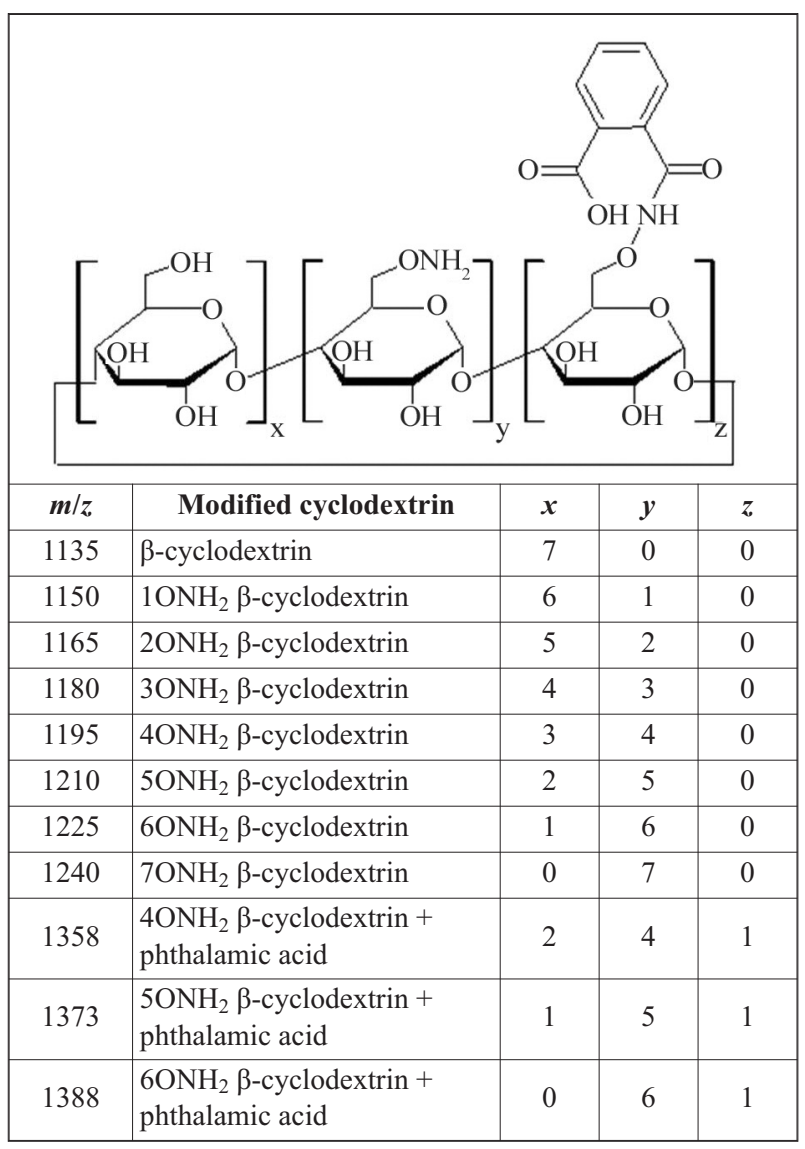

interval (0-72 h), but was suddenly inhibited in higher concentration $(200-1000 \mu \mathrm{g} / \mathrm{ml})$. The aminooxylinker 4 with a number of aminooxy group (Pp) 4.8 in the molecule of cyclodextrin slightly decreased the cell viability with increasing concentration. Figure 5 presents the MTT assay that confirmed the similar trends in oxime hydrogels viability comparing with
Hardy et al. [6], where it was observed the moderate decrease in cell viability toward neonatal rat Schwann cells at higher concentration of the aminooxy-terminated PEGs used as a crosslinking agent for neural tissues hydrogel. The hydrogels from our aminooxylinkers show a similar effect to cells' viability, although the $N, N$-bis(aminooxy)alkanes inhibited viability a little more than the aminooxy-terminated PEGs described in the article. Liquid hydrogels, as HA-1c formed by conjugation of non-cytotoxic HA$\mathrm{CHO}$ [14] $\left(M_{\mathrm{w}}=98 \mathrm{~kg} / \mathrm{mol}\right.$, DS $\left.10 \%\right)$ and $1 \mathrm{c}$, showed good biocompatibility based on cell viability, although the concentration of $1 \mathrm{c}(400 \mu \mathrm{g} / \mathrm{ml})$ inhibited cells in vitro, but the same concentration in oxime hydrogel did not inhibit cells and could be used as a new biocompatible precursor for various biomedical applications.

\subsection{Characterization of HA-imine by NMR}

The crosslinking of linear HA aldehydes and aminocompounds includes hydrogen bonding, ionic (negatively charged carboxyl - positively charged protonated amine), and stronger covalent $(-\mathrm{CH}=\mathrm{N}-)$ bond, which could be directly quantified by ${ }^{1} \mathrm{H}$ NMR spectroscopy. Both aldehydes (HA-CHO and unsaturated $\triangle \mathrm{HA}-\mathrm{CHO}$ ) located in the $\mathrm{N}$-acetylglucosamine unit were used for hydrogel formation (in a molar ratio of amine/aldehyde $1: 1)$ according to the reaction presented in Figure 6.

Because of the known hydrolysis of imine linkage, the reaction kinetics was examined by NMR in the range between 1 and 190 hours. The ${ }^{1} \mathrm{H}$ NMR spectra showed an increase of $\mathrm{HA}-\mathrm{C} 6 \mathrm{H}=\mathrm{N}-\mathrm{O}-$ signal

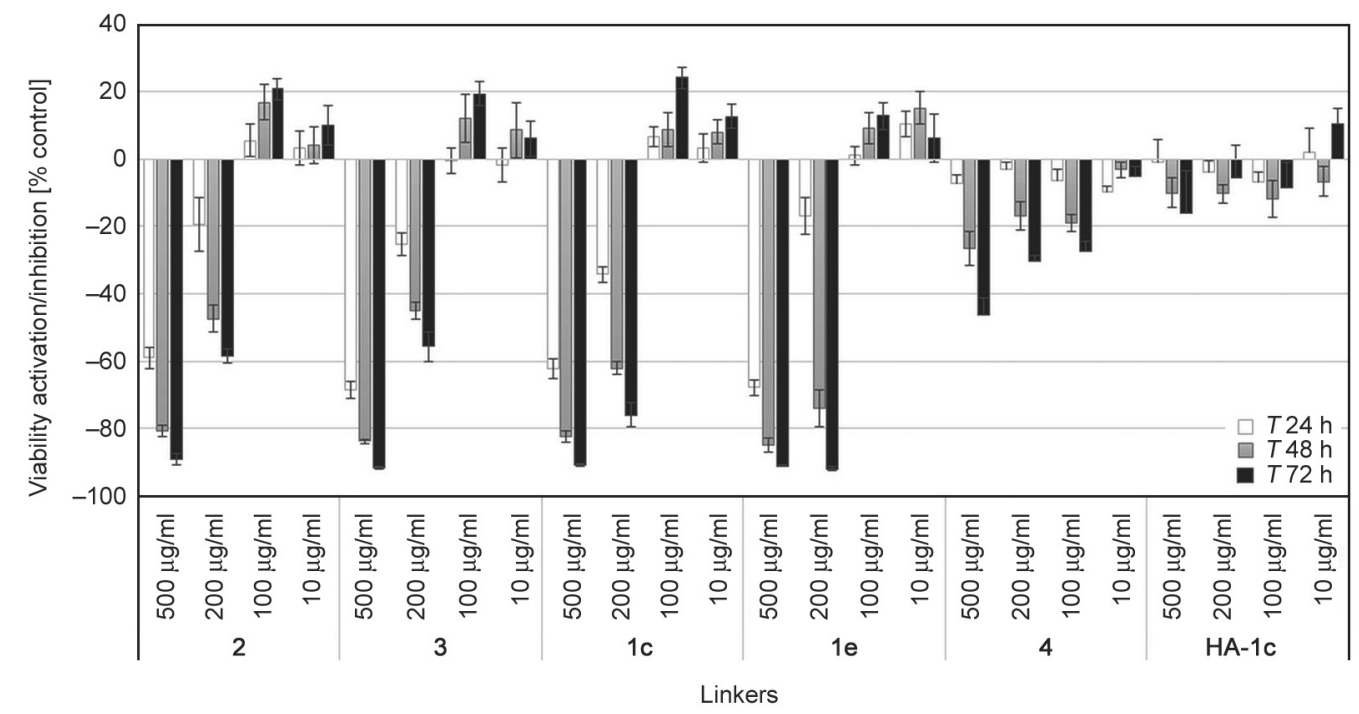

Figure 5. The cytotoxicity of aminooxy-linkers and hydrogel (HA-1c) on 3T3 mouse fibroblast cells. 

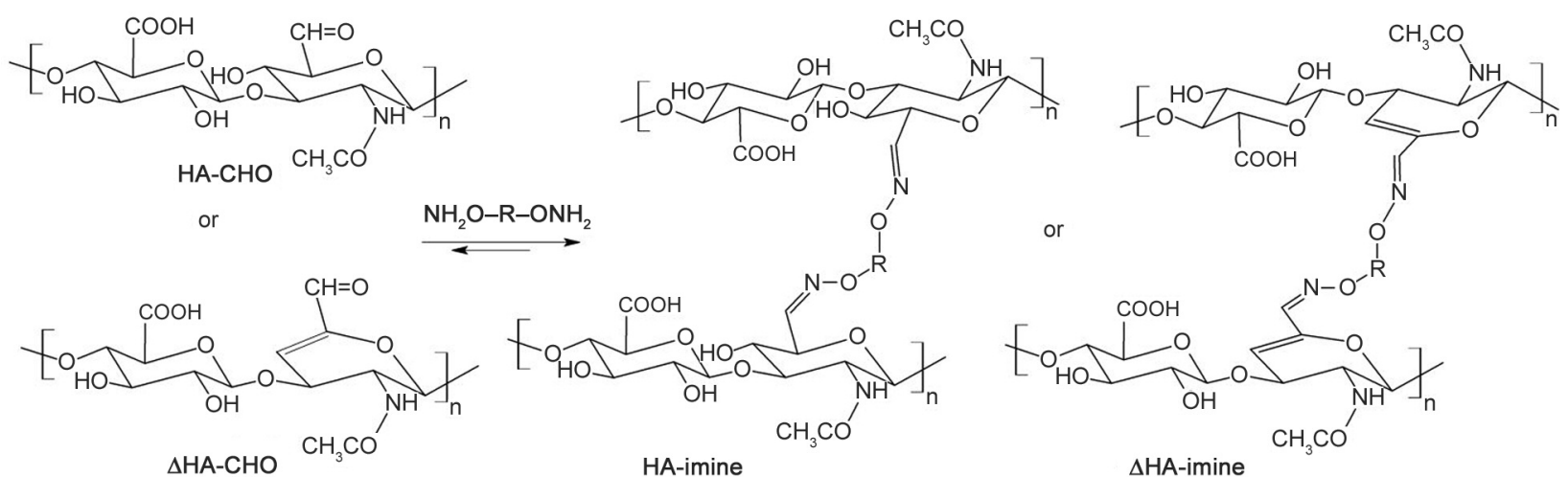

Figure 6. Synthesis of hyaluronan oxime hydrogel from saturated and unsaturated aldehyde of hyaluronan.

related to decreasing signal of the diol form of aldehyde (5.23 ppm) or decreasing signal of unsaturated aldehyde (9.23 and $6.30 \mathrm{ppm}$ ) during the oxime formation. The new signals were detected in the range of chemical shifts from 7.50 to $7.70 \mathrm{ppm}$, which belong to preferential $Z$-isomer and signal at $6.88 \mathrm{ppm}$ to $E$-isomer [23]. ${ }^{1} \mathrm{H}$ NMR spectrum of the unsaturated imine $(\triangle \mathrm{HA}-\mathrm{C} 6 \mathrm{H}=\mathrm{N}-\mathrm{O}-)$, prepared from $\triangle \mathrm{HA}$ $\mathrm{CHO}$, contains two nearby signals of $Z$-isomers belonging to unsaturated and saturated imine that could not be integrated separately (in the range from 7.50 to $7.70 \mathrm{ppm}$ ) and a signal at $5.68 \mathrm{ppm}$ belonging to $\mathrm{C} 4 \mathrm{H}$ of $\triangle \mathrm{HA}-\mathrm{C} 6 \mathrm{H}=\mathrm{N}-\mathrm{O}-$, as shown in Figure 7.
The reaction kinetics of different amine nucleophiles (amine, hydrazide, oxyamine) with the same number of carbons in the chain (hexane) were studied during 190 hours of reaction in $0.9 \%$ saline solution ( $\mathrm{pH} 6.0$ ). Prepared imines are $\mathrm{pH}-$ responsive materials. The imine is effectively formed at $\mathrm{pH} 6$, optimal for the imine formation of hydrazone [13] and oxime. The kinetic of different imines (Figure 8a) confirmed the different reactivity of the linker and increasing hydrolytic stability HA-imine in the order - imine, hydrazone and oxime. The Schiff bases were analyzed by ${ }^{1} \mathrm{H}$ NMR (chemical shifts HA-C6H=N-O- with: 1,6-diaminohexane $\delta 7.5 \mathrm{ppm}$, adipic dihydrazide

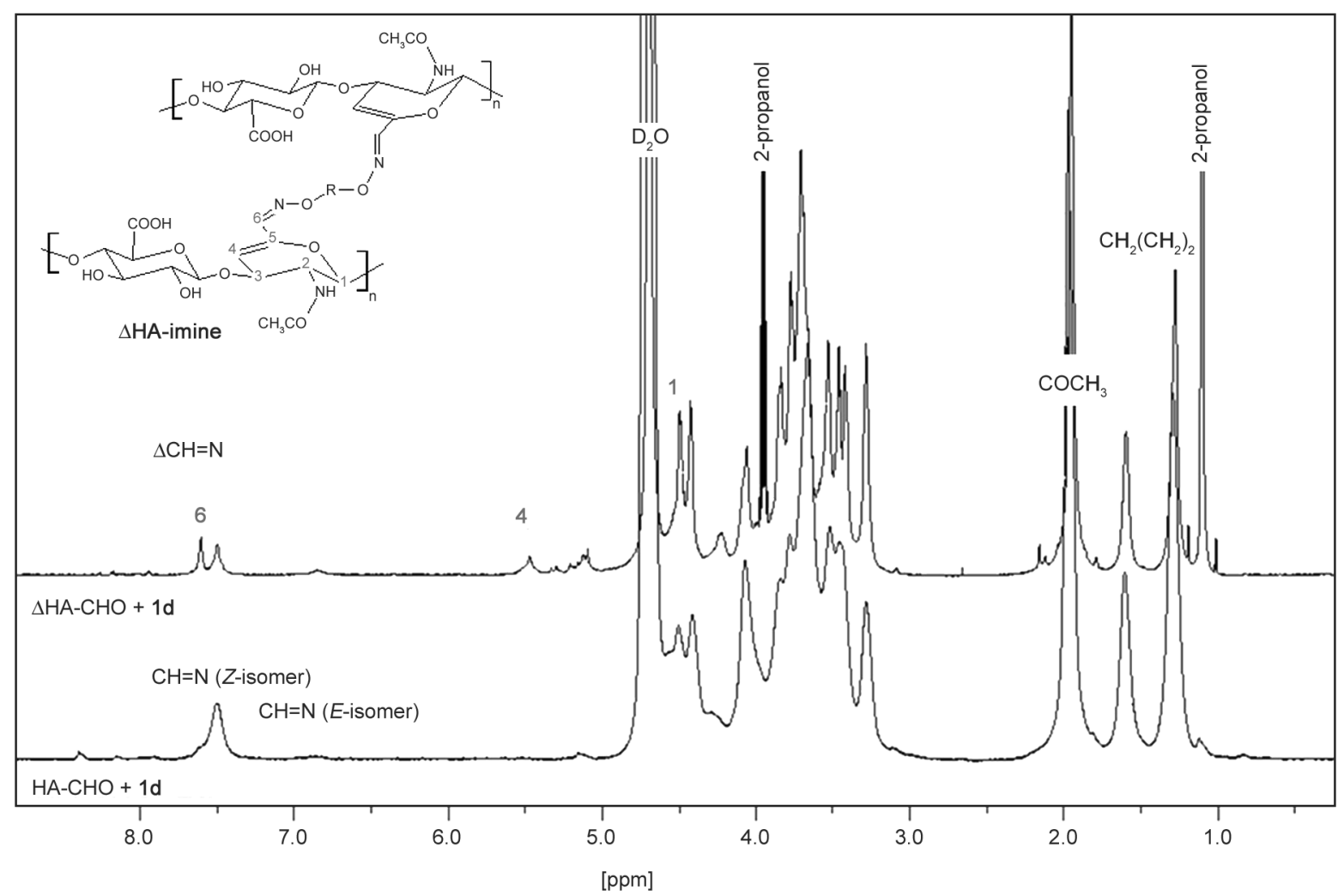

Figure 7. ${ }^{1} \mathrm{H}$ NMR spectra $\left(500 \mathrm{MHz}, \mathrm{D}_{2} \mathrm{O}\right)$ of oxime prepared by reaction of HA-CHO $\left(12.5 \mathrm{mg} / \mathrm{ml}, M_{\mathrm{w}}=47 \mathrm{~kg} / \mathrm{mol}\right.$, DS $40 \%$, DC $10 \%)$ and $1 \% \Delta \mathrm{HA}-\mathrm{CHO}\left(M_{\mathrm{w}}=10 \mathrm{~kg} / \mathrm{mol}\right.$, DS $30 \%$, DS $\left.* 10 \%\right)$ with $N, N$-bis(aminooxy)octane when the molar ratio of $\mathrm{NH}_{2} / \mathrm{CHO}$ was $1 / 1$. 


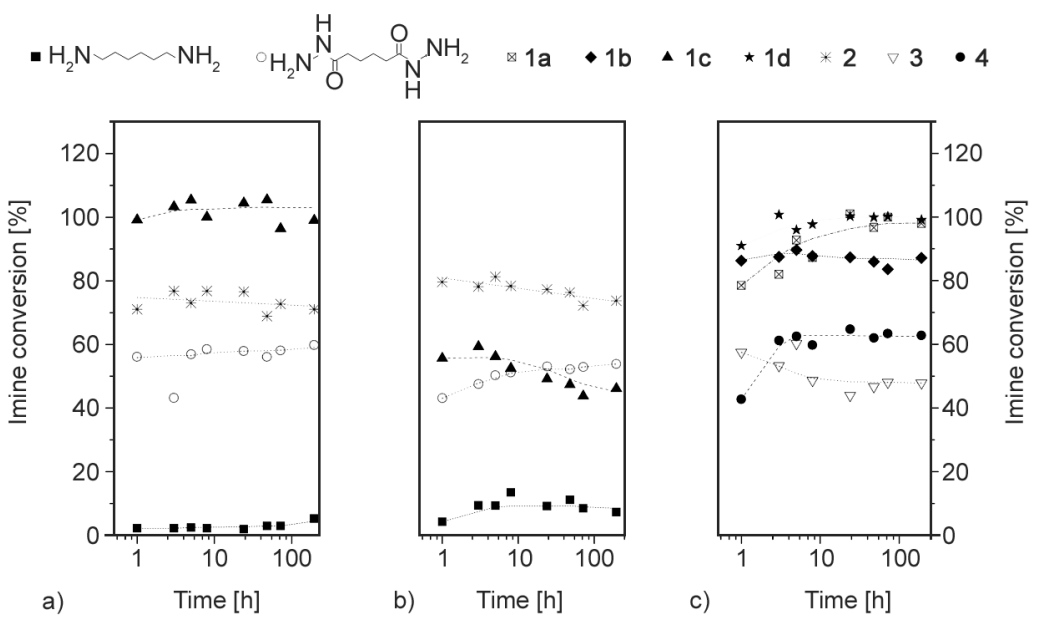

Figure 8. Imine kinetics were determined by NMR spectroscopy at $\mathrm{pH} 6(0.9 \% \mathrm{NaCl})$; imines were formed from $\mathrm{HA}-\mathrm{CHO}$ $\left(12.5 \mathrm{mg} / \mathrm{ml}, M_{\mathrm{w}}=47 \mathrm{~kg} / \mathrm{mol}, \mathrm{DS} 40 \%\right.$, DC 10\%) and different diamino-compounds with 6 carbons (a) or different aminooxy-linker (c) and from $\triangle$ HA-CHO $\left(12.5 \mathrm{mg} / \mathrm{ml}, M_{\mathrm{w}}=10 \mathrm{~kg} / \mathrm{mol}, \mathrm{DS} 30 \%\right.$, DS $\left.10 \%\right)$ with different diamino-compounds with 6 carbons (b) when the molar ratio of $\mathrm{NH}_{2} / \mathrm{CHO}$ was $1 / 1$.

$\delta 7.56 \mathrm{ppm}, \mathbf{1 c} \delta 7.60 \mathrm{ppm}$ and $2 \delta 7.62 \mathrm{ppm})$. Although the presence of a double bound in the imine increased the conversion rate with the amine, the conversion rate with the linear hydrazide and the oxyamine decreased. The hydrolytic stability of the imine and the flexibility of the linker seem to be the main causes of the differences. This unexpected observation could be caused probably by a more rigid polymer chain of $\triangle \mathrm{HA}-\mathrm{CHO}$ in comparison to HA$\mathrm{CHO}$. The unsaturated oxime formed a polysaccharide network more stabilized toward unsaturated imine and made impossible conjugation of the remaining aldehyde, while conjugation of the remaining aldehyde is possible in the composition of unsaturated imine. The crosslinking of HA-CHO using flexible bis-oxyamine in the same ratio of reactive groups led to a higher conversion rate than the conversion of $\triangle \mathrm{HA}-\mathrm{CHO}$, e.g. 1c formed oxime with DI $100 \%$ and unsaturated oxime with DI $60 \%$ (Figure 8b), whereas different trend was observed when more rigid linker was used, e.g. 2.

Figure $8 \mathrm{c}$ illustrates the effect of aminooxy-linker chain on aldehyde conversion during the reaction time. The effect of alkyl-chain length between two aminooxy groups was studied for derivatives, which were soluble in appropriate concentration, with 2 (1a), 3 (1b), 6 (1c) or 8 carbons (1d). Almost insoluble 1e was not tested. According to Hardy et al. [6], we expected increased imine conversion with chain length, but this effect was not observed. As we expected, the higher flexibility of aminooxy-linker (1a-1d) led to a higher imine conversion (DI $80-100 \%$ ) of HA-CHO compared to more rigid aminooxy-linkers
$(2,3,4$ : DI 50-75\%) because of more effective selfassembly to favourable conjugation of more distant aldehyde groups. Cyclodextrins are remarkably rigid due to a ring of hydrogen bonds established between the 2-hydroxyl and 3-hydroxyl groups [24], and this factor probably led to a lower imine conversion of HA-CHO. The differences in imine conversion of bifunctional linkers decreased with a longer reaction time and maturating of the hydrogel.

\subsection{Characterization HA-imine hydrogels by rheology}

Rheology was chosen to assess the stiffness and gelation kinetics of oxime hydrogels. A series of gels was formed with different aminooxy-linkers and HA$\mathrm{CHO} / \Delta \mathrm{HA}-\mathrm{CHO}$ solution $(20 \mathrm{mg} / \mathrm{ml})$, and Young's modulus and swelling degree characterized them. Storage modulus ( $G^{\prime}$ in 3 minutes) for cyclodextrin conjugates was chosen as a suitable parameter for comparing the final oxime materials.

Experiments in $0.9 \% \mathrm{NaCl}$ (Figure 9, Table 3) proved that gelation time slightly decreases with the number of aminooxy groups in the linker in the order bis (aminooxy) linker $\left(T_{\mathrm{g}}>35 \mathrm{~s}\right)$, tris (aminooxy) linker $\left(T_{\mathrm{g}}=25 \mathrm{~s}\right)$, hexakis (aminooxy) $\left(T_{\mathrm{g}}=16 \mathrm{~s}\right)$ and heptakis(aminooxy) linkers $\left(T_{\mathrm{g}}<7 \mathrm{~s}\right)$. The very short gelation time can be limiting in the injection of hydrogel during low invasive application.

The small addition of DMSO $(1.25 \% \mathrm{w} / \mathrm{v})$ to the linker enhanced its solubility in an aqueous solution and accelerated an arrangement to hydrogel and gelation. The DMSO effect on $T_{\mathrm{g}}$ was significant even if $\mathbf{1 b}$, the highly aqueous soluble linker, was used. When 


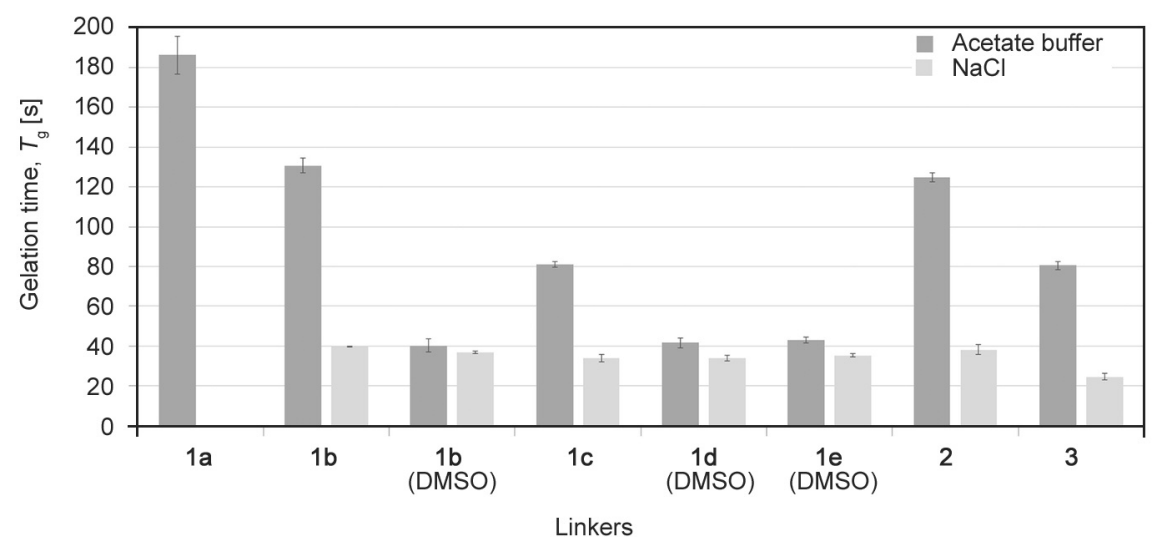

Figure 9. The gelation time in acetate buffer ( $\mathrm{pH} 6) / 0.9 \% \mathrm{NaCl}$ with $20 \mathrm{mg} / \mathrm{ml} \mathrm{HA}-\mathrm{CHO}\left(M_{\mathrm{w}}=314 \mathrm{~kg} / \mathrm{mol}\right.$, DS $\left.9 \%\right)$ and the reaction ratio of aldehyde/oxyamine groups was 1/1. (DMSO): the aminooxy-linker was added in acetate buffer $/ \mathrm{NaCl}$ solution contained DMSO with a final concentration of $1.25 \% \mathrm{w} / \mathrm{v}$ in hydrogels.

Table 3. The effect of 4 on rheological properties of hydrogels in $0.9 \% \mathrm{NaCl}, 20 \mathrm{mg} / \mathrm{ml} \mathrm{HA}-\mathrm{CHO}\left(M_{\mathrm{w}}=342 \mathrm{~kg} / \mathrm{mol}\right.$, DS 9\%).

\begin{tabular}{|c|c|c|c|c|c|c|c|c|c|}
\hline Linker $^{1}$ & $P_{p}^{2}$ & $\begin{array}{c}\text { Ratio } \\
\mathrm{NH}_{2} / \mathrm{CHO}\end{array}$ & $\begin{array}{c}m_{(\text {Linker) }}{ }^{3} \\
{[\mathrm{mg} / \mathrm{ml}]}\end{array}$ & $\begin{array}{l}T_{\mathrm{g}} \\
{[\mathrm{s}]}\end{array}$ & $\begin{array}{c}S D T_{\mathrm{g}} \\
{[\mathrm{s}]}\end{array}$ & $\begin{array}{c}G^{\prime} 3 \min ^{4} \\
{[\mathrm{~Pa}]}\end{array}$ & $\begin{array}{c}S D G^{\prime} 3 \text { min } \\
{[\mathrm{Pa}]}\end{array}$ & $\begin{array}{c}G^{\prime} \text { strain sweep } \\
{[\mathrm{Pa}]}\end{array}$ & $\begin{array}{c}S D G^{\prime} \\
\mathrm{Pa}]\end{array}$ \\
\hline $4(5 / 6)$ & 5.56 & $1: 1$ & 0.992 & 15.7 & 2.8 & 111.6 & 17.8 & 1243.9 & 84.1 \\
\hline $4(5 / 6)$ & 5.56 & $2: 1$ & 1.983 & 12.0 & 1.4 & 182.3 & 24.2 & & \\
\hline $4(7)$ & 6.83 & $1: 1$ & 0.817 & $<6.5$ & - & 196.9 & 17.2 & & \\
\hline 4 & 4.86 & $1: 1$ & 1.121 & 14.0 & 1.0 & 177.0 & 13.5 & 1159.8 & 44.8 \\
\hline $4(7)$ & 6.83 & $1: 2$ & 0.409 & $<6.5$ & - & 117.2 & 10.4 & & \\
\hline $4(7)$ & 6.83 & $1: 4$ & 0.204 & 13.5 & 3.1 & 32.4 & 61.4 & & \\
\hline $4(7)$ & 6.83 & $1: 8$ & 0.102 & 104.0 & 11.5 & 5.7 & 1.4 & & \\
\hline $1 b$ & 2.00 & $1: 1$ & 0.400 & 39.4 & 1.6 & 158.8 & 32.9 & 2079.5 & 331.1 \\
\hline
\end{tabular}

${ }^{1}$ number of aminooxy groups in major cyclodextrin derivatives in chromatographically separated fractions is mentioned in brackets, ${ }^{2} P_{\mathrm{p}}-$ number of aminooxy groups in linker molecule,

${ }^{3} m$ - the weight of linker per $1 \mathrm{ml}$ of hydrogel,

${ }^{4} G^{\prime} 3$ min: elastic modulus at $3^{\text {rd }}$ minute.

the gelation process was studied in an acetate buffer (Figure 9), the same trend in the kinetics of gelation was observed, but with a little higher gelation time $\left(T_{\mathrm{g}}>40 \mathrm{~s}\right)$. There was indicated that stabilization of intermediate during imine formation by a hydrogen bond with organic carboxylates [25] was not so effective as a catalytic effect of $\mathrm{NaCl}$. The catalytic effect of $\mathrm{NaCl}$ was assigned to the stabilization of the charged transition states that favoured the crucial rate-limiting elimination (dehydration) step, as was published by Wang et al. [26].

Although 4 crosslinked HA-CHO very quickly, hydrogels had lower mechanical stiffness than hydrogels prepared with low molecular bifunctional linkers. Differences between several different multikis(6aminooxy-6-deoxy)- $\beta$-cyclodextrin were negligible from the perspective of possible applications. The decrease of $\mathrm{NH}_{2} / \mathrm{CH}=\mathrm{O}$ ratio from 1:1 to 1:8 (Table 3) led to an increase of gelation time and resulted in a reduction of gel stiffness according to $G^{\prime}$. The cyclodextrin was chosen as the aminooxy-linker for its unique ability to form inclusion complexes. Still, due to the low mechanical strength of hydrogel, we decided not to study the complex properties potentially valuable for pharmacotherapy.

\subsection{Hydrogel stiffness characterized by Young's modulus $(E)$}

Hydrogel composition can easily explain the difference in swelling behaviour and stiffness (Young's modulus) of different hydrogels. Apart from the type of amine, the length of the linker influenced the hydrogel properties. The mixture of amine with HA$\mathrm{CHO}$ formed only a solution mainly formed by unreacted HA-CHO because of the low stability of imine. The hydrazide formed soft hydrogel with higher $S W$, and oxyamine formed stiff hydrogel (Table 4) (lower $S W$ ). The hydrolytic stability of imine increased, the Young's modulus increased too.

The stiffness of hydrogel measured by Young's modulus was similar for unsaturated oxime and saturated oxime and was not dependent on the flexibility of 
Table 4. Mechanical properties (Young's modulus and swelling degree) of hydrogels prepared by 48 hours crosslinking $20 \mathrm{mg} / \mathrm{ml} \mathrm{HA}-\mathrm{CHO}\left(M_{\mathrm{w}}=342 \mathrm{~kg} / \mathrm{mol}\right.$, DS $9 \%)(0.9 \% \mathrm{NaCl})$ with six carbon compounds differing by an amine group.

\begin{tabular}{|l|c|c|c|c|c|}
\hline \multirow{2}{*}{ Amine } & \multirow{2}{*}{$\begin{array}{c}\boldsymbol{E} \\
{[\mathrm{kPa}]}\end{array}$} & \multirow{2}{*}{$\begin{array}{c}\boldsymbol{S} \boldsymbol{D} \\
{[\mathrm{kPa}]}\end{array}$} & \multicolumn{3}{c|}{$\begin{array}{c}\text { SW } \\
{[\mathbf{\%}]}\end{array}$} \\
\cline { 4 - 6 } & & & $\mathbf{1 d}$ & $\mathbf{4 d}$ & $\mathbf{7 d}$ \\
\hline C6-amine & no gel & & & & \\
\hline C6-hydrazide & 9,0 & 0,6 & 250 & 100 & dissolved \\
\hline C6-oxyamine & 16,0 & 1,1 & 110 & 113 & 118 \\
\hline
\end{tabular}

the linker. In a comparison of results Youngs' moduli of hydrogels prepared from HA-CHO with molecular weight 342 and $88 \mathrm{~kg} / \mathrm{mol}$, it was found that the higher $M_{\mathrm{w}}$ led to stiffer hydrogels. The materials prepared with two the longest linear linkers $(\mathbf{1 d}, \mathbf{1 e})$ showed the lowest stiffness during the stress $\left(E<6 \mathrm{kPa}\right.$ for HA-CHO: $\left.M_{\mathrm{w}}=82 \mathrm{~kg} / \mathrm{mol}\right)$ and higher swelling degree (Figure 10). It was probably caused by the hydrophobic character of linkers, which led to their hydrophobic interaction. As was shown in Figure 8, the DI was comparable with short linear linkers (1a-1c), but stiffness of hydrogels of $\mathbf{1 d}, \mathbf{1 e}$ was lower, probably because of low intermolecular and high intramolecular crosslinking of hydrophilic polysaccharide. Swelling behaviour is one of the crucial properties of hydrogels because it determines the hydrogel ability to uphold water and its diffusion

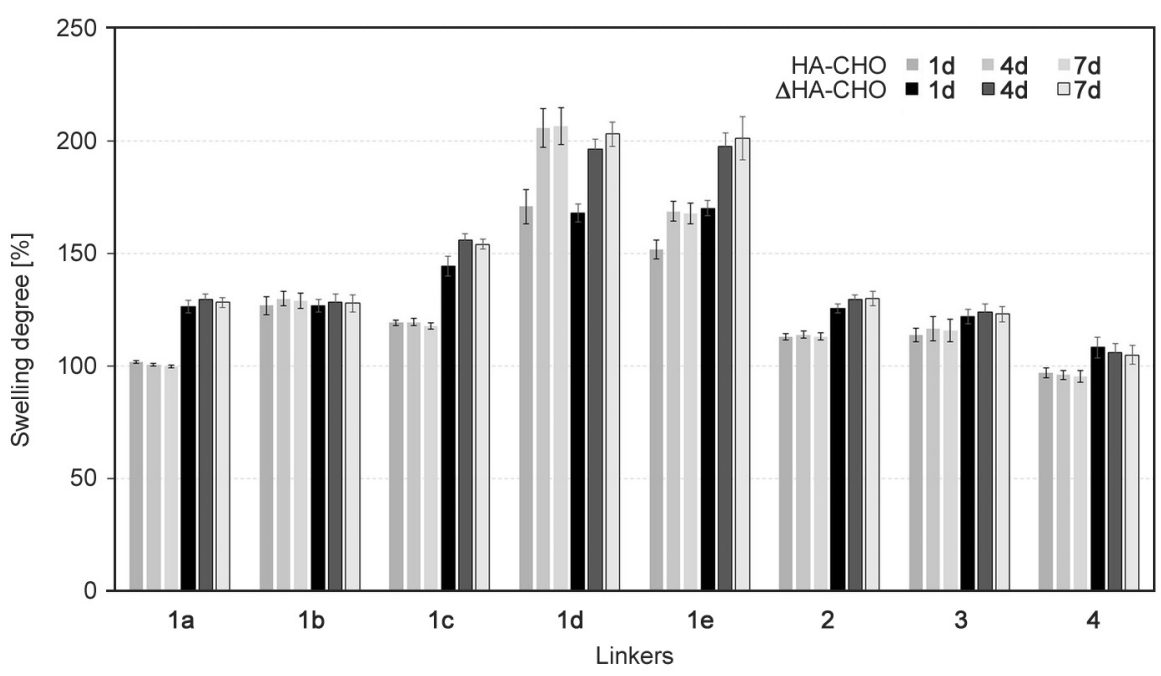

Figure 10. The swelling degree of hydrogels in PBS ( $\mathrm{pH} 6.0$ ) prepared with different oxyamines and $2 \% \Delta \mathrm{HA}-\mathrm{CHO}$ $(88 \mathrm{~kg} / \mathrm{mol}, \mathrm{DS} 4 \%$, DS* $6 \%$ ) or $2 \%$ HA-CHO $(82 \mathrm{~kg} / \mathrm{mol}$, DS $10 \%)$ and after 24 hours of gel maturing and after 1,2 and 7 days of swelling.

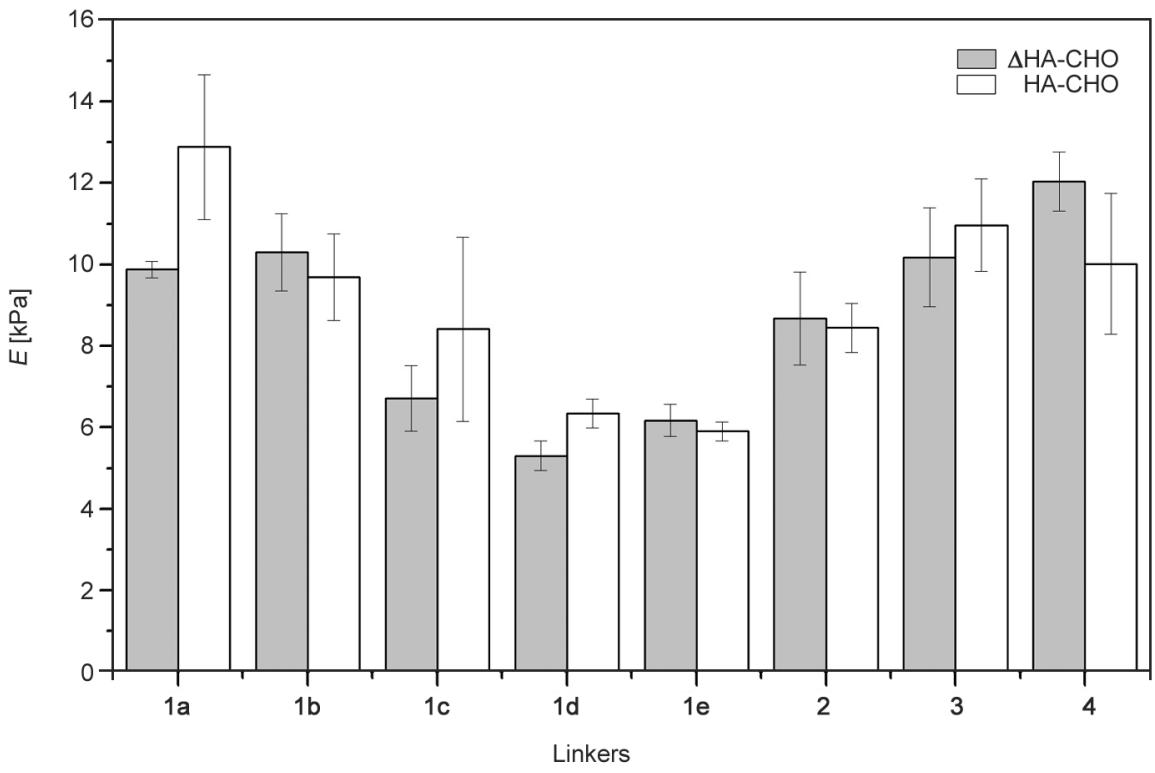

Figure 11. Effect of aminooxy-linker to Young's modulus in $0.9 \% \mathrm{NaCl}$ solution (pH 6) after 24 hours, $20 \mathrm{mg} / \mathrm{ml} \mathrm{HA-CHO}$ $\left(M_{\mathrm{W}}=82 \mathrm{~kg} / \mathrm{mol}, \mathrm{DS} 9 \%\right), \Delta \mathrm{HA}-\mathrm{CHO}\left(M_{\mathrm{W}}=88 \mathrm{~kg} / \mathrm{mol}, \mathrm{DS} 4 \%\right.$, DS* $\left.6 \%\right)$. 
through 3D structure. Moreover, the swelling also supports cell growth and survival because it helps diffusion of nutrients, oxygen, and other metabolites [4]. Although the only lower number of aminooxy groups in trifunctional aminooxy-linker $\mathbf{3}$ reacted with HA-CHO (lower DI) in comparison to 2, this hydrogel was stiffer (according to Youngs' moduli, Figure 11).

\section{Conclusions}

The hyaluronan hydrogels are promising for biomedical application, and many factors can affect their mechanical properties. In this study, we prepared a series of new aminooxy-linkers and found out the influence of their structural characteristics on the condensation reaction with two types of aldehyde groups attached to HA. The higher reactivity of several bis(aminooxy) alkanes (ethane, propane, hexane, octane, decane) in comparison to more rigid bis- or multikis(aminooxy) derivatives (benzene and $\beta$-cyclodextrin) were confirmed by NMR analysis. It was found that more rigid linkers decreased the imine conversion, while the length of the linear linker did not influence the conversion rate. Surprisingly, modified hyaluronan crosslinked with oxyamine showed higher imine conversion for HA-CHO in comparison with $\triangle$ HA-CHO, mainly when flexible oxyamines were used. The probable reason was a more rigid polymer chain of $\triangle \mathrm{HA}-\mathrm{CHO}$ in comparison to more flexible (sterically more available) HA-CHO.

The rheological analysis confirmed that the number of aminooxy groups in aminooxy-linker led to shortening of the gelation time and similar mechanical properties as bis(aminooxy)linker. Youngs' moduli reported that the hydrophobic character of aminooxy-linker increased, and the mechanical stiffness of hydrogel decreased. The gelation time for all studied aminooxy-linkers was shorter than $40 \mathrm{~s}$ and therefore presented hyaluronan oxime hydrogels could be an excellent alternative for applications where the fast formation of hydrogels is required (visco-supplementation, 3D printing).

\section{Acknowledgements}

The authors are grateful for the financial support and great advice from Ass. Prof. Vladimír Velebný.

\section{References}

[1] Xu J., Liu Y., Hsu S-H.: Hydrogels based on Schiff base linkages for biomedical applications. Molecules, 24, 3005 (2019).

https://doi.org/10.3390/molecules24163005

[2] Mero A., Campisi M.: Hyaluronic acid bioconjugates for the delivery of bioactive molecules. Polymers, 6, 346-369 (2014).

https://doi.org/10.3390/polym6020346

[3] Litwiniuk A., Krejner T., Speyrer M. S., Gauto A. R., Grzela T.: Hyaluronic acid in inflammation and tissue regeneration. Wounds, 28, 78-88 (2016).

[4] Pandit A. H., Madzumar N., Sharif A.: Periodate oxidized hyaluronic acid-based hydrogel scaffolds for tissue engineering applications. International Journal of Biological Macromolecules, 137, 853-869 (2019).

https://doi.org/10.1016/j.ijbiomac.2019.07.014

[5] Koivusalo L., Karvinen J., Sorsa E., Jönkkäri I., Väliaho J., Kallio P., Ilmarinen T., Miettinen S., Skottman H., Kellomäki M.: Hydrazone crosslinked hyaluronan-based hydrogels for therapeutic delivery of adipose stem cells to treat corneal defects. Materials Science and Engineering: C, 85, 68-78 (2018).

https://doi.org/10.1016/j.msec.2017.12.013

[6] Hardy J. G., Lin P., Schmidt C. E.: Biodegradable hydrogels composed of oxime crosslinked poly(ethylene glycol), hyaluronic acid and collagen: A tunable platform for soft tissue engineering. Journal of Biomaterials Science, Polymer Edition, 26, 143-161 (2015).

https://doi.org/10.1080/09205063.2014.975393

[7] Baker A. E. G., Tam R. Y., Shoichet M. S.: Independently tuning the biochemical and mechanical properties of 3D hyaluronan-based hydrogels with oxime and Diels-Alder chemistry to culture breast cancer spheroids. Biomacromolecules, 18, 4373-4384 (2017).

https://doi.org/10.1021/acs.biomac.7b01422

[8] Bartheldyová E., Effenberg R., Mašek J., Procházka L., Knötigová P. T., Kulich P., Hubatka F., Velínská K., Zelníčková J., Zouharová D., Fojtíková M., Hrebík D., Plevka P., Mikulík R., Miller A. D., Macaulay S., Zyka acid surface modified liposomes prepared via orthogonal aminoxy coupling: Synthesis of nontoxic aminoxylipids based on symmetrically $\alpha$-branched fatty acids, preparation of liposomes by microfluidic mixing, and targeting to cancer cells expressing CD44. Bioconjugate Chemistry, 29, 2343-2356 (2018). https://doi.org/10.1021/acs.bioconjchem.8b00311

[9] Baker A. E. G., Bahlmann L. C., Tam R. Y., Liu J. C., Ganesh A. N., Mitrousis N., Marcellus R., Spears M., Bartlett J. M. S., Cescon D. W., Bader G. D., Shoichet M. S.: Benchmarking to the gold standard: Hyaluronanoxime hydrogels recapitulate xenograft models with in vitro breast cancer spheroid culture. Advanced Materials, 31, 1901166 (2019).

https://doi.org/10.1002/adma.201901166 
[10] Novoa-Carballal R., Carretero A., Pacheco R., Reis R. L., Pashkuleva I.: Star-like glycosaminoglycans with superior bioactivity assemble with proteins into microfibers. Chemistry - A European Journal, 24, 1434114345 (2018).

https://doi.org/10.1002/chem.201802243

[11] Li Z., Liu L., Chen Y.: Dual dynamically crosslinked thermosensitive hydrogel with self-fixing as a postoperative anti-adhesion barrier. Acta Biomaterialia, 110, 119-128 (2020).

https://doi.org/10.1016/j.actbio.2020.04.034

[12] Baker A. E. G., Cui H., Balios B. G., Ing S., Yan P., Wolfer J., Wright T., Dang M., Gan N. Y., Cooke M. J., Ortín-Martínez A., Wallece V. A., van der Kooy D., Devenyi R., Shoichet M. S.: Stable oxime-crosslinked hyaluronan-based hydrogel as a biomimetic vitreous substitute. Biomaterials, 271, 120750 (2021). https://doi.org/10.1016/j.biomaterials.2021.120750

[13] Šedová P., Buffa R., Šilhár P., Kovářová L., Vágnerová H., Bednařík J., Basarabová I., Hejlová L., Ščigalková I., Šimek M., Velebný V.: The effect of hydrazide linkers on hyaluronan hydrazone hydrogels. Carbohydrate Polymers, 216, 63-71 (2019). https://doi.org/10.1016/j.carbpol.2019.04.011

[14] Šedová P., Buffa R., Kettou S., Huerta-Angeles G., Hermannová M., Leierová V., Šmejkalová D., Moravcová M., Velebný V.: Preparation of hyaluronan polyaldehyde - A precursor of biopolymer conjugates. Carbohydrate Research, 371, 8-15 (2013). https://doi.org/10.1016/j.carres.2013.01.025

[15] Buffa R., Šedová P., Basarabová I., Moravcová M., Wolfová L., Bobula T., Velebný V.: $\alpha, \beta$-unsaturated aldehyde of hyaluronan - Synthesis, analysis and applications. Carbohydrate Polymers, 134, 293-299 (2015). https://doi.org/10.1016/j.carbpol.2015.07.084

[16] Kalia J., Raines R. T.: Hydrolytic stability of hydrazones and oximes. Angewandte Chemie International Edition, 47, 7523-7526 (2008). https://doi.org/10.1002/anie.200802651

[17] Schneider L. A., Korber A., Grabbe S., Dissemond J.: Influence of $\mathrm{pH}$ on wound-healing: A new perspective for wound-therapy? Archives of Dermatological Research, 298, 413-420 (2007).

https://doi.org/10.1007/s00403-006-0713-x

[18] Dolan E. B., Kovarova L., O’Neill H., Pravda M., Sulakova R., Scigalkova I., Velebny V., Daro D., Braun N., Cooney G. M., Bellavia G., Straino S., Cavanagh B. L., Flanagan A., Kelly H. M., Duffy G. P., Murphy B. P.: Advanced material catheter (AMCath), a minimally invasive endocardial catheter for the delivery of fast-gelling covalently cross-linked hyaluronic acid hydrogels. Journal of Biomaterials Applications, 33, 681692 (2018).

https://doi.org/10.1177/0885328218805878
[19] Dong X-Y., Gao S-X., Zhang Y-J., Zhang Y., Wang L. Synthesis and characterization of series of methoxysubstituted salamo-type compounds having more flexible O-alkyl chain. Asian Journal of Chemistry, 26, 6918-6920 (2014).

https://doi.org/10.14233/ajchem.2014.17417

[20] Sadamoto R., Niikura K., Ueda T., Monde K., Fukuhara N., Nishimura S-I.: Control of bacteria adhesion by cell-wall engineering. Journal of the American Chemical Society, 126, 3755-3761 (2004)

https://doi.org/10.1021/ja039391i

[21] Yi L., Sun H., Wu Y-W., Triola G., Waldmann H., Goody R. S.: A highly efficient strategy for modification of proteins at the $\mathrm{C}$ terminus. Angewandte Chemie, 49, 9417-9421 (2010).

https://doi.org/10.1002/anie.201003834

[22] Jiang Y. L., Krosky D. J., Seiple L., Stivers J. T.: Uracildirected ligand tethering: An efficient strategy for uracil DNA glycosylase (UNG) inhibitor developmentt. Journal of the American Chemical Society, 127, 17412 17420 (2005).

https://doi.org/10.1021/ja055846n

[23] Buffa R., Nešporová K., Basarabová I., Halamková P., Svozil V., Velebný V.: Synthesis and study of branched hyaluronic acid with potential anticancer activity. Carbohydrate Polymers, 223, 115047 (2019).

https://doi.org/10.1016/j.carbpol.2019.115047

[24] Saenger W., Jacob J., Gessler K., Steiner T., Hoffmann D., Sanbe H., Koizumi K., Smith S. M., Takaha T.: Structures of the common cyclodextrins and their larger analogues - Beyond the doughnut. Chemical Reviews, 98, 1787-1802 (1998).

https://doi.org/10.1021/cr9700181

[25] Wang S., Gurav D., Oommen O. P., Varghese O. P.: Insights into the mechanism and catalysis of oxime coupling chemistry at physiological $\mathrm{pH}$. Chemistry - A European Journal, 21, 5980-5985 (2015). https://doi.org/10.1002/chem.201406458

[26] Wang S., Nawale G. N., Kadekar S., Oommen O. P., Jena N. K., Chakraborty S., Hilborn J., Varghese O. P.: Saline accelerates oxime reaction with aldehyde and KETO substrates at physiological pH. Scientific Report, 8, 2193 (2018).

https://doi.org/10.1038/s41598-018-20735-0 